\title{
Pneumatosis cystoides intestinalis secondary to chronic jejunal diverticulitis
}

\author{
A. M. SAMMON* \\ M.B., F.R.C.S.
}

\author{
A. J. Malcolm $\dagger$ \\ M.B., Ch.B.
}

Departments of *Surgery and $\nmid$ Pathology, Southern General Hospital, Glasgow

\begin{abstract}
Summary
Pneumoperitoneum due to pneumatosis cystoides intentinalis is reported in a patient with congenital jejunal diverticula. Attention is drawn to the potential diagnostic problems in patients with known intestinal pathology who present with pneumoperitoneum.
\end{abstract}

\section{Introduction}

Pneumatosis cystoides intestinalis is an uncommon condition found in association with obstructive respiratory disease (Doub and Shea, 1960) and with various lesions of the intestinal tract: peptic ulcer, gastric neoplasm, enteritis, appendicitis, intestinal obstruction, colitis (Koss, 1952), and diverticular disease of the colon (Shallal et al., 1974). It may arise as a complication of sigmoidoscopy and of colonic biopsy (Marshak, Blum and Eliasoph, 1956). In many cases the condition arises without a known underlying cause. It may affect the small or large intestine, and can give rise to a variety of symptoms, the most serious following spontaneous rupture of the cysts, producing pneumoperitoneum.

\section{Case report}

A 63-year-old male had complained of midabdominal pain intermittently for 25 years and had been treated with antacids. For 2 years before his present admission the pain was worse and more frequent and was associated with anorexia, weight loss, borborygmi, flatulence and frequent passage of loose offensive stools. He was known to have had emphysema for many years.

A barium meal in May, 1977, showed extensive jejunal diverticula and gross stasis. He was treated with antibiotics and cholestyramine. There was some temporary improvement. Two weeks before the present admission all his symptoms had become severe and there was one short episode of sudden severe epigastric pain radiating through to the back. An X-ray of abdomen showed multiple fluid levels in keeping with jejunal diverticula, free air under both hemidiaphragms and interposition of small bowel above the liver. He was admitted with a diagnosis of a perforated jejunal diverticulum.
On admission the patient did not complain of abdominal pain. The abdomen was distended but soft with no guarding. There were increased bowel sounds which were of normal pitch.

At laparotomy the presence of free air in the peritoneal cavity was confirmed and there was no peritonitis. Many large jejunal diverticula were present on the mesenteric border from the duodenojejunal junction distally for $25 \mathrm{~cm}$. No perforation was present in any of the diverticula. The affected bowel was resected and end-to-end anastomosis carried out. Postoperative recovery was uneventful.

Histology confirmed the presence of multiple jejunal diverticula which were chronically inflamed and the presence of muscle coats established that they were of congenital origin. Numerous sub-o mucosal air cysts lined by flattened endothelial cells in keeping with dilated lymphatic channels were noted within the jejunum and the diverticula. These cysts were partially surrounded by foreign body giant cells (Fig. 1) typical of pneumatosis cystoides intestinalis.

\section{Comment}

Smith and Welter (1967) suggested that breaks in the mucosal continuity in inflammatory conditions of the intestine allowed gas to enter, and become entrapped in, the submucosa or serosa and the resulting cysts represented dilated lymphatic channels. The inflammatory changes in the diverticula in this case support the above suggestion. Congenital jejunal diverticula are a hitherto unreported cause of pneumatosis cystoides intestinalis.

Doub and Shea (1960) suggested that any asymptomatic patient with radiological evidence of pneumoperitoneum should be suspected of having pneumatosis cystoides intestinalis. Smith and Welter (1967) also discussed the diagnostic confusion that may arise between perforated peptic ulcer and pneumoperitoneum due to pneumatosis cystoides intestinalis. This case further demonstrates the problem of diagnosis which may arise between pneumoperitoneum due to pneumatosis cystoides intestinalis, and pneumoperitoneum due to the 


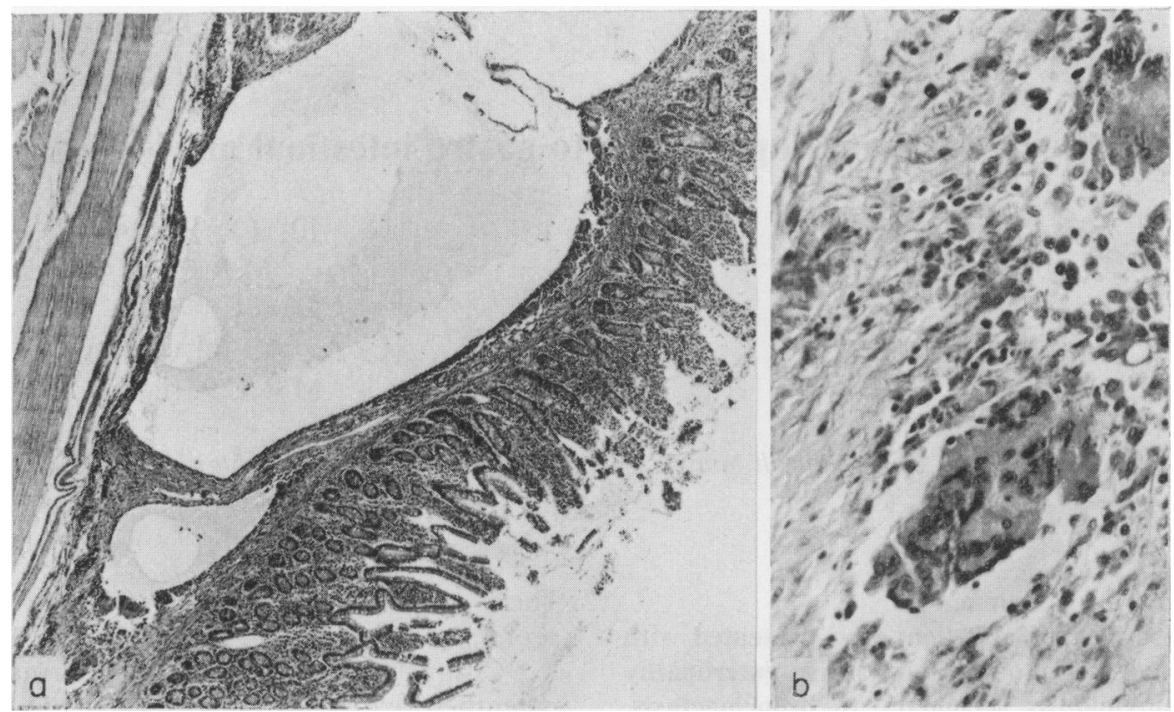

Fig. 1. (a) Submucosal cysts in jejunum $(\mathrm{HE}, \times 37)$ and $(\mathrm{b})$ the giant cells lining the cysts $(\mathrm{HE}, \times 230)$.

underlying disease process causing pneumatosis cystoides intestinalis.

Pneumatosis cystoides intestinalis should be considered in all cases of pneumoperitoneum where symptoms and signs of peritonitis are absent or atypical.

\section{Acknowledgments}

We thank Dr G. P. Crean and Mr G. C. MacBain for permission to report this case, and the Department of Radiology for their help.

\section{References}

Doub, H.P. \& ShEA, J.J. (1960) Pneumatosis of cystoides intestinalis. Journal of the American Medical Association, 172, 1238.

Koss, L.G. (1952) Abdominal gas cysts (pneumatosis cystoides intestinorum hominis). Archives of Pathology, 53, 523.

Marshak, R.H., Blum, S.D. \& Eliasoph, J. (1956) Pneumatosis involving the left side of the colon. Journal of the American Medical Association, 161, 1626.

Shallal, J.A., Van Heerden, J.A., Bartholomew, L.G. \& CAIG, J.C. (1974) Pneumatosis cystoides intestinalis. Proceedings. Mayo Clinic, 49, 180.

Smith, B.H. \& Welter, L.H. (1967) Pneumatosis intestinalis. American Journal of Clinical Pathology, 48, 455. 